RESEARCH ArTiCLE

Published October 2, 2020

\title{
Temporal Clinical and Laboratory RESPONSE TO INTERLEUKIN-6 RECEPTOR Blockade With Tocilizumab IN 89 Hospitalized Patients With COVID-19 Pneumonia
}

\section{AUTHORS}

Daria S. Fomina, $\mathrm{MD}^{1,2}$, Mar'yana A. Lysenko, $\mathrm{MD}^{1,3}$, Irina P. Beloglazova, $\mathrm{MD}^{1,3}$, Zinaida Yu. Mutovina, $\mathrm{MD}^{1,4}$, Nataliya G. Poteshkina, $\mathrm{MD}^{1,3}$, Inna V. Samsonova, $\mathrm{MD}^{1}$, Tat'yana S. Kruglova, $\mathrm{MD}^{1}$, Anton A. Chernov, $\mathrm{MD}^{1,5}$, Alexander V. Karaulov, $\mathrm{MD}^{2}$

CORRESPONDING AUTHOR

Anton A.Chernov

Pekhotnaya str., 3

Moscow, 123182

sbornaya1med@yandex.ru

+ 7-499-196-39-36

\section{RESEARCH IN CONTEXT}

\section{Evidence before this study}

Morbidity and mortality in severe COVID-19 disease caused by SARS-2 is associated with evidence of systemic inflammation. Two small uncontrolled series $(n=15$ and 21$)$ reported clinical and laboratory improvements in COVID-19 patients treated with tocilizumab. Most of these patients also received corticosteroids.

\section{Added value of this study}

We treated 89 hospitalized patients with COVID-19 pneumonia and heightened systemic inflammation (elevated serum $C$ reactive protein and interleukin-6 levels) with an infusion of tocilizumab. None of these patients received corticosteroids. We found rapid improvements in clinical indices, in CRP levels, and in lymphocyte counts 1-2 days after tocilizumab infusion. Nearly $90 \%$ of patients who were not receiving mechanical ventilation survived to hospital discharge and only 
one of 72 such patients died. Mortality was nearly $60 \%$ in patients receiving mechanical ventilation and was predicted by elevated CRP levels $(>30 \mathrm{mg} / \mathrm{L})$ and low lymphocyte counts $(<1000 / \mathrm{uL})$.

\section{IMPLICATIONS OF ALL THE AVAILABLE EVIDENCE}

Interleukin-6 is an important driver of both clinical and inflammatory abnormalities of COVID-19. Controlled studies are urgently needed to confirm a clinical benefit of IL-6 blockade. Additional measures will be needed to treat COVID-19 patients receiving mechanical ventilation.

\section{AUTHORS}

Daria S. Fomina, PhD, allergologist-immunologist, head of the Center of Allergy and Immunolo$\mathrm{gy}^{1}$, associate professor of clinical immunology and allergology ${ }^{2}$, ORCID: 0000-0002-5083-6637, email: daria_fomina@mail.ru

Mar'yana A. Lysenko, MD, professor, department of General Therapy ${ }^{3}$, Chief Medical Officer', ORCID: 0000-0001-6010-7975, email: gkb52@zdrav.mos.ru

Irina P. Beloglazova, $\mathrm{PhD}$, general practitioner-pulmonologist, head of the Therapeutic Department $^{1}$, ORCID: 0000-0002-2266-1497, email: beloglazova.irina@gmail.com

Zinaida Yu. Mutovina, $\mathrm{PhD}$, associate professor in the Department of General Therapy, Cardiology, and Functional Diagnostics ${ }^{4}$, rheumatologist, head of the Rheumatology Department ${ }^{1}$, ORCID: 0000-0001-5809-6015, email: zmutovina@mail.ru

Nataliya G. Poteshkina, MD, professor, head of the Department of General Therapy ${ }^{3}$, head of the University Clinic ${ }^{1}$, ORCID: 0000-0001-9803-2139, email: nat-pa@yandex.ru

Inna V. Samsonova, PhD, Deputy Chief Medical Officer ${ }^{1}$, ORCID: 0000-0002-1228-1765, email: innasamsonova@yandex.ru

Tat'yana S. Kruglova, allergist-immunologist, head of the department of Allergy and Immunology ${ }^{1}$, ORCID: 0000-0002-4949-9178, email: surckova.t@yandex.ru

Anton A. Chernov, Clinical pharmacology therapist ${ }^{1}$, junior researcher, Research Institute of Molecular and Personalized Medicine ${ }^{5}$, ORCID: 0000-0001-6209-387X, email: sbornay1med@ yandex.ru

Alexander V. Karaulov, PhD, professor, head of the Department of Clinical Immunology and Allergology ${ }^{2}$, ORCID: 0000-0002-1930-5424

\section{AFFILIATED INSTITUTIONS}

${ }^{1}$ City Clinical Hospital No.52 of Moscow Healthcare Department, Moscow, Russia;

${ }^{2}$ First Sechenov Moscow State Medical University of the Ministry of Healthcare of the Russian Federation, Moscow, Russia;

${ }^{3}$ Pirogov Russian National Research Medical University (RNRMU) of the Ministry of Healthcare, Moscow, Russia;

${ }^{4}$ Federal State Institution of Additional Professional Education "Central State Medical Academy" of the President of the Russian Federation, Moscow, Russia; 
${ }^{5}$ Russian Medical Academy of Continuing Professional Education, Moscow, Russia.

\section{SUGGESTED CITATION}

Fomina DS, Lysenko MA, Beloglazova IP, Mutovina ZY, Poteshkina NG, Samsonova IV, Kruglova TS, Chernov AA, Karaulov AV. Temporal Clinical and Laboratory Response to Interleukin-6 Receptor Blockade With Tocilizumab in 89 Hospitalized Patients With COVID-19 Pneumonia. Pathogens and Immunity. 2020;5(1):327-341. PubMed PMID. doi: 10.20411/pai.v5i1.392

\section{ABSTRACT}

Background: Pandemic COVID-19 pneumonia due to SARS-2 is an important cause of morbidity and mortality. Emerging evidence links poor outcomes to an inflammatory cytokine storm.

Methods: We treated 89 hospitalized patients with COVID-19 pneumonia and heightened systemic inflammation (elevated serum $\mathrm{C}$ reactive protein and interleukin-6 levels) with an infusion of tocilizumab (TCZ), a human monoclonal IgG1 antibody to the interleukin-6 receptor.

Results: Clinical and laboratory evidence of improvement was evident when baseline and 1-2day post-infusion indices were compared. Among the 72 patients receiving supplemental oxygen without mechanical ventilation, severity of condition on the NEWS2 scale scores fell from 5 to $2(P<0.001)$, C reactive protein levels fell from 95 to $14 \mathrm{mg} / \mathrm{L}(P<0.001)$, and lymphocyte counts rose from 900 to $1000 / \mathrm{uL}(P=0.036)$. Sixty-three of 72 patients were discharged from the hospital, one patient died, and eight patients remained in the hospital at the time of this writing. Among the 17 patients receiving mechanical ventilation, despite a rapid decrease in CRP levels from 89 to $35 \mathrm{mg} / \mathrm{L}(P=0.014)$ and early improvements in NEWS2 scores in 10 of 17 patients, 10 patients ultimately died and the other seven remain in the hospital at the time of this writing. Overall, mortality was only seen in patients who had markedly elevated CRP levels ( $>30 \mathrm{mg} / \mathrm{L}$ ) and low lymphocyte counts $(<1000 / \mathrm{uL})$ before TCZ administration.

Conclusions: Inflammation and lymphocytopenia are linked to mortality in COVID-19. Inhibition of IL-6 activity by administration of tocilizumab, an anti-IL-6 receptor antibody, is associated with rapid improvement in both CRP and lymphocyte counts and in clinical indices. Controlled clinical trials are needed to confirm the utility of IL-6 blockade in this setting. Additional interventions will be needed for patients requiring mechanical ventilation.

Keywords: Covid-19, SARS-CoV-2, pneumonia, cytokine storm, IL-6, tocilizumab

\section{INTRODUCTION}

Currently there are no approved effective treatments for patients with COVID-19. Clinical management of this infection is supportive of the provision of supplementary oxygen and mechanical ventilation as warranted. Therefore, there is an urgent unmet need for effective treatment that will alter the morbid course of this infection and prevent mortality.

The COVID-19 pandemic is caused by infection with a new, readily transmissible RNA virus, SARS-2. SARS-2 is a single-stranded coronavirus that enters cells after binding to the angiotensin-converting enzyme type 2 (ACE-2) receptors that are highly expressed by nasal epithelium, type 2 alveolar cells, and gut epithelial cells, but are also present in other organs $[\underline{1}, \underline{2}, \underline{3}]$. While this 
virus can infect persons of all ages, morbidity and mortality are highest among older persons and persons with underlying conditions such as obesity, cardiovascular disease, hypertension, and diabetes $[\underline{4}, \underline{5}]$ who appear to be at greater risk for the development of pneumonia. Those severely ill with pneumonia develop an aggressive progression of disease that is characterized by elevated levels of inflammatory cytokines in many ways resembling a cytokine storm that has been described in other settings such as, for example, after administration of chimeric antigen receptor (CAR) $\mathrm{T}$ cells in acute lymphocyte leukemia []].

Here we report our experience in treating serious COVID-19 pneumonia with tocilizumab (TCZ), a recombinant humanized monoclonal IgG1 antibody to the interleukin-6 receptor that binds both membrane and soluble receptors.

In this uncontrolled study of 89 persons with COVID-19 pneumonia who were admitted to a Moscow Territorial COVID center, we found evidence of clinical improvement following TCZ administration as well as improvement in laboratory indices that are linked to COVD-19-induced cytokine storm.

\section{METHODS}

\section{Patients and Intervention}

We treated 89 patients admitted to the Moscow City Clinical Hospital No. 52 (a territorial COVID center) with a diagnosis of COVID-19 pneumonia. SARS-CoV-2 infection was confirmed by RT-PCR of nasopharyngeal swabs; pneumonia was diagnosed by CT scan. Tocilizumab $400 \mathrm{mg}$ was administered intravenously based upon recent Russian Federal clinical recommendations for treatment of SARS-CoV-2 infection [7]].

To standardize initial and serial assessments of patients' clinical status, the NEWS2 scale (the latest version of the National Early Warning Score) was used. NEWS2 scores were based on assessment of six physiological indices: respiratory rate; oxygen saturation; systolic blood pressure; heart rate; level of consciousness; and temperature $[\underline{8}, \underline{9}]$.

\section{Laboratory and Radiology}

Routine clinical laboratory assays were performed in the hospital's clinical laboratories. Clinical and laboratory information was extracted from the patients' medical records. C reactive protein (CRP) in plasma was measured by immunoturbidimetry (Beckman Coulter, Krefeld, Germany). Interleukin-6 (IL-6) levels in plasma were measured by electrochemiluminescence (Siemens Medical Solutions Diagnostics, Siemens Healthcare, Erlangen, Germany). CT scans were read by experienced radiologists who scored results by severity using the criteria shown in Figure 1.

\section{Statistical Analysis}

Data are presented as medians and interquartile ranges (IQR). Statistical data processing was carried out using the application program "IBM SPSS STATISTICS V-22" software. For comparison of quantitative indicators, the Mann-Whitney $U$ test was used, and for qualitative characteristics, the Fisher $\chi 2$ test was used. Differences were considered significant if $\mathrm{p}<0.05$. 


\begin{tabular}{|c|c|c|}
\hline Signs & Severity & Typical Picture \\
\hline $\begin{array}{l}\text { - No more than } 3 \text { seal focuses } \\
\text { of ground glass type } \\
\text { - }<3 \mathrm{~cm} \text { in maximum diame- } \\
\text { ter }\end{array}$ & $\begin{array}{l}\text { Mild } \\
(\mathrm{CT}-1)\end{array}$ & \\
\hline $\begin{array}{l}\text { - More than } 3 \text { seal focuses of } \\
\text { ground glass type, } \\
\text { - Less than } 50 \% \text { involvement } \\
\text { by visual assessment }\end{array}$ & $\begin{array}{l}\text { Moderate } \\
(\mathrm{CT}-2)\end{array}$ & \\
\hline $\begin{array}{l}\text { - Seal focuses of ground glass } \\
\text { type combined with focuses } \\
\text { of consolidation } \\
\text { - } 50-70 \% \text { involvement by visu- } \\
\text { al assessment }\end{array}$ & $\begin{array}{l}\text { Medium-heavy } \\
\text { (CT-3) }\end{array}$ & \\
\hline $\begin{array}{l}\text { - Diffuse compaction of lung } \\
\text { tissue of ground glass type } \\
\text { - More than } 75 \% \text { involvement } \\
\text { by visual assessment }\end{array}$ & $\begin{array}{l}\text { Severe } \\
(\mathrm{CT}-4)\end{array}$ & \\
\hline
\end{tabular}

Figure 1. Clinical assessment of pneumonia severity based on computed tomography (CT) scores. Scoring method: Mild (CT-1) - no more than three ground-glass opacities of $<3 \mathrm{~cm}$ maximum diameter. Moderate (CT-2) - more than three ground-glass opacities; less than 50\% involvement by visual assessment. Medium-heavy (CT-3) - ground-glass opacities and pulmonary consolidation; 50$70 \%$ involvement by visual assessment. Severe (CT-4) - diffuse ground-glass opacities with or without consolidation; more than $75 \%$ involvement by visual assessment.

\section{RESULTS}

Clinical characteristics of the 89 patients before administration of TCZ are shown in Table 1. Seventeen of these patients (19\%) were receiving mechanical ventilation (MV), while 72 (81\%) were treated with supplemental oxygen without mechanical ventilation (No MV). Ten of these 72 patients were receiving high-flow oxygen.

Slightly over half of the patients in the MV group were 50 years old or older, while two-thirds of patients who were in the No MV group were 50 years old or older. Half of the MV patients were women, while only approximately one-third (27/92) of the No MV patients were women. None of these demographics were significantly different between the MV and No MV groups. Pre-existing comorbidities were present in $77 \%$ patients (3/17) of the MV group and 67\% (48/72) of the No MV group (no statistical difference, NSD). Hypertension was present in $41 \%$ of the MV group and in $31 \%$ of the No MV group (NSD). Obesity was present in 53\% of the MV group and 19\% of the No MV group $(P=0.04)$. Underlying diabetes was seen in only $1 / 17 \mathrm{MV}$ patients and in 9/72 
Table 1. Clinical characteristics of patients before administration of Tocilizumab

\begin{tabular}{|c|c|c|c|}
\hline Characteristics: & $\begin{array}{c}\text { Mechanical } \\
\text { ventilation } \\
(\mathrm{MV})(\mathbf{n}=\mathbf{1 7}) \\
\end{array}$ & $\begin{array}{c}\text { No Mechanical } \\
\text { ventilation } \\
(\text { No MV) }(n=72)\end{array}$ & All $(n=89)$ \\
\hline Female, n (\%) & $9(53)$ & $27(38)$ & $34(43)$ \\
\hline \multicolumn{4}{|l|}{ Age category, n (\%) } \\
\hline$<50$ y.o. & $8(47)$ & $24(33)$ & $32(36)$ \\
\hline $50-69$ y.o. & $5(29)$ & $40(56)$ & $45(51)$ \\
\hline$\geq 70$ y.o. & $4(24)$ & $8(11)$ & $12(14)$ \\
\hline \multicolumn{4}{|c|}{ Pre-existent conditions, $\mathbf{n}(\%)$} \\
\hline Any condition & $13(77)$ & $48(67)$ & $61(69)$ \\
\hline Hypertension & $7(41)$ & $22(31)$ & $29(33)$ \\
\hline Diabetes & $1(6)$ & $9(13)$ & $10(11)$ \\
\hline Chronic lung disease & $1(6)$ & $5(7)$ & $6(7)$ \\
\hline Obesity & $9(53)$ & $14(19)$ & $23(26)$ \\
\hline \multicolumn{4}{|l|}{ Severity } \\
\hline $\begin{array}{l}\text { Lymphocytes }<100010^{6} \mathrm{uL} \text {, } \\
\mathrm{n}(\%)\end{array}$ & $15(88)$ & $42(58)$ & $57(64)$ \\
\hline $\begin{array}{l}\text { Median Serum IL6 pg/mL } \\
(\mathrm{IQR})^{\mathrm{a}}\end{array}$ & $122(47-390)^{*}$ & $43(19-75)^{\star}$ & $49(25-99)$ \\
\hline $\begin{array}{l}\text { Median Serum CRP mg/L } \\
\text { (IQR) }\end{array}$ & $89(70-191)$ & $95(45-150)$ & $94(54-157)$ \\
\hline Febrile n (\%) & $12(71)$ & $67(93)$ & $79(89)$ \\
\hline \multicolumn{4}{|c|}{ Lung CT score on admission ${ }^{\star *}, \mathrm{n}(\%)$} \\
\hline $\begin{array}{l}1 \\
2 \\
3 \\
4 \\
\end{array}$ & $\begin{array}{c}1(5.9) \\
3(17.6) \\
5(29.4) \\
8(47.1)\end{array}$ & $\begin{array}{c}3(4.2) \\
37(51,4) \\
29(40.3) \\
3(4.1) \\
\end{array}$ & $\begin{array}{c}4(5.1) \\
40(50.6) \\
34(43) \\
11(13.9) \\
\end{array}$ \\
\hline $\begin{array}{l}\text { Day of TCZ initiation } \\
\text { since disease onset- } \\
\text { median (IQR) }\end{array}$ & $12(7-12)$ & $10(7-11)$ & $10(7-11)$ \\
\hline
\end{tabular}

Presented are the main clinical indices for patients who were or were not receiving mechanical ventilation at initiation of Tocilizumab treatment.

Clinical indices did not differ between the groups excepting: *plasma IL-6 levels were higher in the mechanical ventilation group than in the non-mechanical ventilation group ( $\mathrm{p}=0.001 \mathrm{Mann}-\mathrm{Whitney} \mathrm{U}$ test) and

${ }^{* *} \mathrm{CT}$ Scores that were more severe in the MV group than in the non-mechanical ventilation group (median 3(IQR 3-4) vs median 2(IQR 2-3, p=0.01 Mann-Whitney U test). 
No MV patients. Chronic lung disease was seen in 1/17 MV patients and 5/72 No MV patients (NSD).

Circulating lymphocyte numbers were low $(<1000 / \mathrm{uL})$ in $88 \%$ of MV patients $(15 / 17)$ and in $58 \%$ of the No MV patients (42/72). Serum IL-6 levels were elevated and were higher in the MV group, with median levels of $122 \mathrm{pg} / \mathrm{mL}$ (IQR 47-390), than in the No MV group (48 pg/mL (IQR 19-75, $P=0.001)$ ). Serum levels of $C$ reactive protein (CRP), an acute phase reactant that is driven by IL-6, were elevated in both groups, with medians of $89 \mathrm{mg} / \mathrm{L}$ (IQR 70-191) in the MV group and $95 \mathrm{mg} / \mathrm{L}$ (IQR 45-150) in the No MV group (NSD). CT scores were more severe in the MV group, with median scores of 3 versus median scores of 2 in the No MV group $(P=0.01)$. Nearly half of the patients (8/17) in the MV group had scores of 4, while in the No MV group only three of 72 (4\%) had scores of 4. Among MV patients, TCZ administration was begun on median day 12 of illness (IQR 7-12 days), and on median day 10 of illness (IQR 7-11 days) among No MV patients.

Among the 89 patients who were treated with TCZ, 74 had been treated for a median of nine days

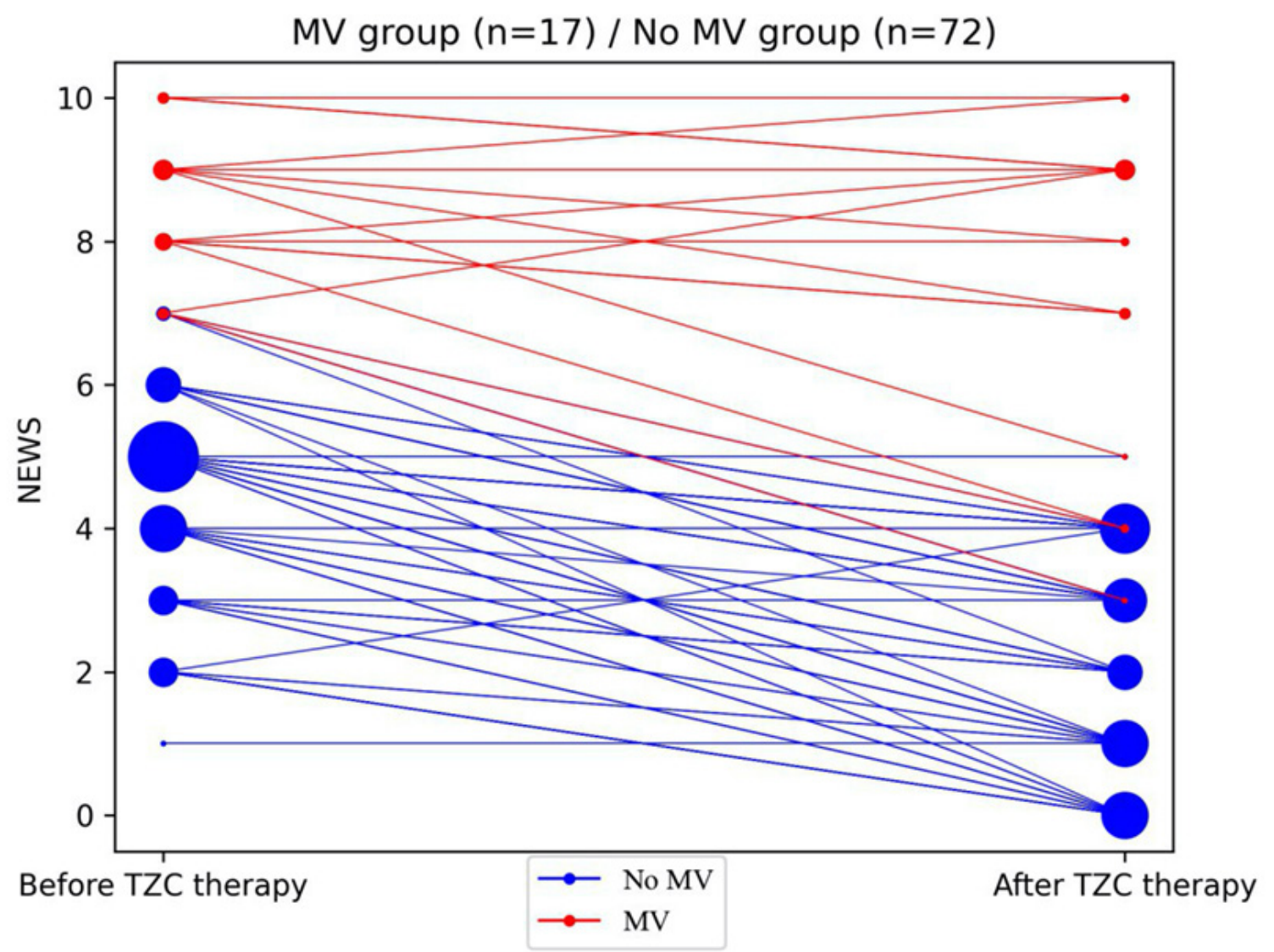

Figure 2. Changes in NEWS2 severity score after TCZ therapy.

NEWS2 severity score is shown before (day of TCZ initiation) and 24-48 h after launching TCZ therapy for 17 patients who were receiving mechanical ventilation (MV) (red) or who were not receiving mechanical ventilation (blue) prior to therapy. The size of the circle reflects the number of patients with a given severity score. 
with hydroxychloroquine+azithromycin+lopinavir/ritonavir before TCZ treatment, four had been treated for a median of nine days with hydroxychloroquine+azithromycin before TCZ treatment, and 11 had been treated for a median of nine days with lopinavir/ritonavir before TCZ treatment.

Figure 2 shows the changes in clinical status as determined by NEWS2 scores, from baseline at the initiation of tocilizumab to 1-2 days after TCZ administration. In the No MV group, median NEWS2 scores fell from 5 to 2 ( $\mathrm{p}<0.001$, Mann-Whitney $U$ test) with $65 / 72$ patients experiencing a decrease reflecting clinical improvement, 6/72 remaining unchanged, and 1/72 with increasing scores reflecting clinical deterioration. None required mechanical ventilation. In the MV group, median NEWS2 scores remained at 8, with 10/17 experiencing a decrease reflecting improvement, 4/17 remaining unchanged, and 3/17 experiencing an increase in scores reflecting deterioration. Laboratory results at baseline before TCZ administration and 1-2 days after treatment are shown in Table 2. CRP levels fell in the No MV group from a median of $95 \mathrm{mg} / \mathrm{L}$ pre-treatment to $13.5 \mathrm{mg} / \mathrm{L} 1-2$ days after treatment $(\mathrm{p}<0.001)$. CRP levels also fell in the MV group from 89 $\mathrm{mg} / \mathrm{L}$ before TCZ administration to $35 \mathrm{mg} / \mathrm{L} 1-2$ days after TCZ treatment $(P=0.014)$. Absolute lymphocyte counts rose from a median of $900 / \mathrm{uL}$ to $1000 / \mathrm{uL}(P=0.036)$ in the No MV group, but there was no significant change in the MV group (from 700 to 800 cells/uL). In both groups, LDH, AST, ALT, and fibrinogen levels did not change significantly although sampling was in-

Table 2. Early changes in laboratory indices after TCZ

\begin{tabular}{|c|c|c|c|}
\hline Indicators & Baseline & Post-treatment & $\mathbf{p}$ \\
\hline $\begin{array}{l}\mathrm{CRP} \mathrm{mg} / \mathrm{L}, \text { No } \mathrm{MV} \\
\text { Reference range }<6 \mathrm{mg} / \mathrm{L}\end{array}$ & $\begin{array}{c}n=72 \\
95(45: 150)\end{array}$ & $\begin{array}{c}\mathrm{n}=72 \\
13.5(5.8: 26.0)\end{array}$ & $<0.001^{\star}$ \\
\hline $\begin{array}{l}\mathrm{CRP} \mathrm{mg} / \mathrm{L}, \mathrm{MV} \\
\text { Reference range }<6 \mathrm{mg} / \mathrm{L}\end{array}$ & $\begin{array}{c}\mathrm{n}=17 \\
89.0(70.0: 191.0)\end{array}$ & $\begin{array}{c}\mathrm{n}=17 \\
35.0(16.0: 105.0)\end{array}$ & 0,014 \\
\hline $\begin{array}{l}\text { Lymphocytes/ uL, No MV } \\
\text { Reference range } 1200-3000 / \mathrm{uL}\end{array}$ & $\begin{array}{c}n=72 \\
900(600: 1,200)\end{array}$ & $\begin{array}{c}n=72 \\
1000(800: 1,400)\end{array}$ & 0,036 \\
\hline $\begin{array}{l}\text { Lymphocytes/ uL MV } \\
\text { Reference range 1200-300/uL }\end{array}$ & $\begin{array}{c}\mathrm{n}=17 \\
700(500: 800)\end{array}$ & $\begin{array}{c}\mathrm{n}=17 \\
800(400: 1300)\end{array}$ & NSD \\
\hline $\begin{array}{l}\text { Leukocytes } \times 10^{9} / \mathrm{LNoMV} \\
\text { Reference range } 4-9 \times 10^{9} / \mathrm{L}\end{array}$ & $\begin{array}{c}\mathrm{n}=71 \\
5,5(4: 7)\end{array}$ & $\begin{array}{c}\mathrm{n}=71 \\
4(4: 5)\end{array}$ & NSD \\
\hline $\begin{array}{l}\text { Leukocytes } \times 10^{9 /} / \mathrm{L}, \mathrm{MV} \\
\text { Reference range } 4-19 \times 10^{9} / \mathrm{L}\end{array}$ & $\begin{array}{c}\mathrm{n}=17 \\
5,8(4: 12)\end{array}$ & $\begin{array}{c}\mathrm{n}=17 \\
9,1(4: 11)\end{array}$ & 0.02 \\
\hline $\begin{array}{l}\text { Neutrophils } \times 10^{9 /} / \mathrm{L}, \text { No MV } \\
\text { Reference range } 2-7.5 \times 10^{9} / \mathrm{L}\end{array}$ & $\begin{array}{c}n=71 \\
4,2(2: 6)\end{array}$ & $\begin{array}{c}n=71 \\
2,8(2: 5)\end{array}$ & NSD \\
\hline $\begin{array}{l}\text { Neutrophils } 10^{9} / \mathrm{L} \mathrm{MV} \\
\text { Reference range } 2-7.5 \times 10^{9} / \mathrm{L}\end{array}$ & $\begin{array}{c}\mathrm{n}=17 \\
3,9(3: 9)\end{array}$ & $\begin{array}{c}\mathrm{n}=17 \\
7,4(4: 11)\end{array}$ & $<0.001^{\star}$ \\
\hline
\end{tabular}

Presented are laboratory indices of patients who were receiving mechanical ventilation (MV) or were not receiving mechanical ventilation (No MV) at initiation of Tocilizumab treatment (baseline) and 1-2 days later. Numbers of patients, medians and interquartile range (IQR) are indicated. NSD- no significant difference. 
complete. The absolute leukocyte count increased significantly in the MV group from 5,800/uL to $9,100 / \mathrm{uL}(P=0.02)$, while in the No MV group there was a non-significant decrease from $5,500 / \mathrm{uL}$ to $4,000 / \mathrm{uL}$. The absolute neutrophil count increased after TCZ treatment in the MV group from $3,900 / \mathrm{uL}$ to $7,400 / \mathrm{uL}(P=0.001)$, while a decrease from $4,200 / \mathrm{uL}$ to $2,800 / \mathrm{uL}$ in the No MV group was not significant.

\section{Clinical Outcomes}

At the time of dataset freezing, between days 6 and 26 after TCZ administration, 63 patients had been discharged from the hospital, 11 had died, and 15 patients remained in the hospital (Figure 3 ). In the No MV group, one patient died (1\%), 63 patients were discharged from the hospital (88\%), and eight patients (11\%) remained in the hospital at a median of 11 days (range 6-23) after TCZ administration. In the MV group, 10 patients died (59\%), seven patients remained in the hospital at a median 13 days (range 9-24) after TCZ administration, and no patients were discharged from the hospital (Figure 3).

Combined data on clinical and laboratory indices among patients who died $(n=11)$ and those

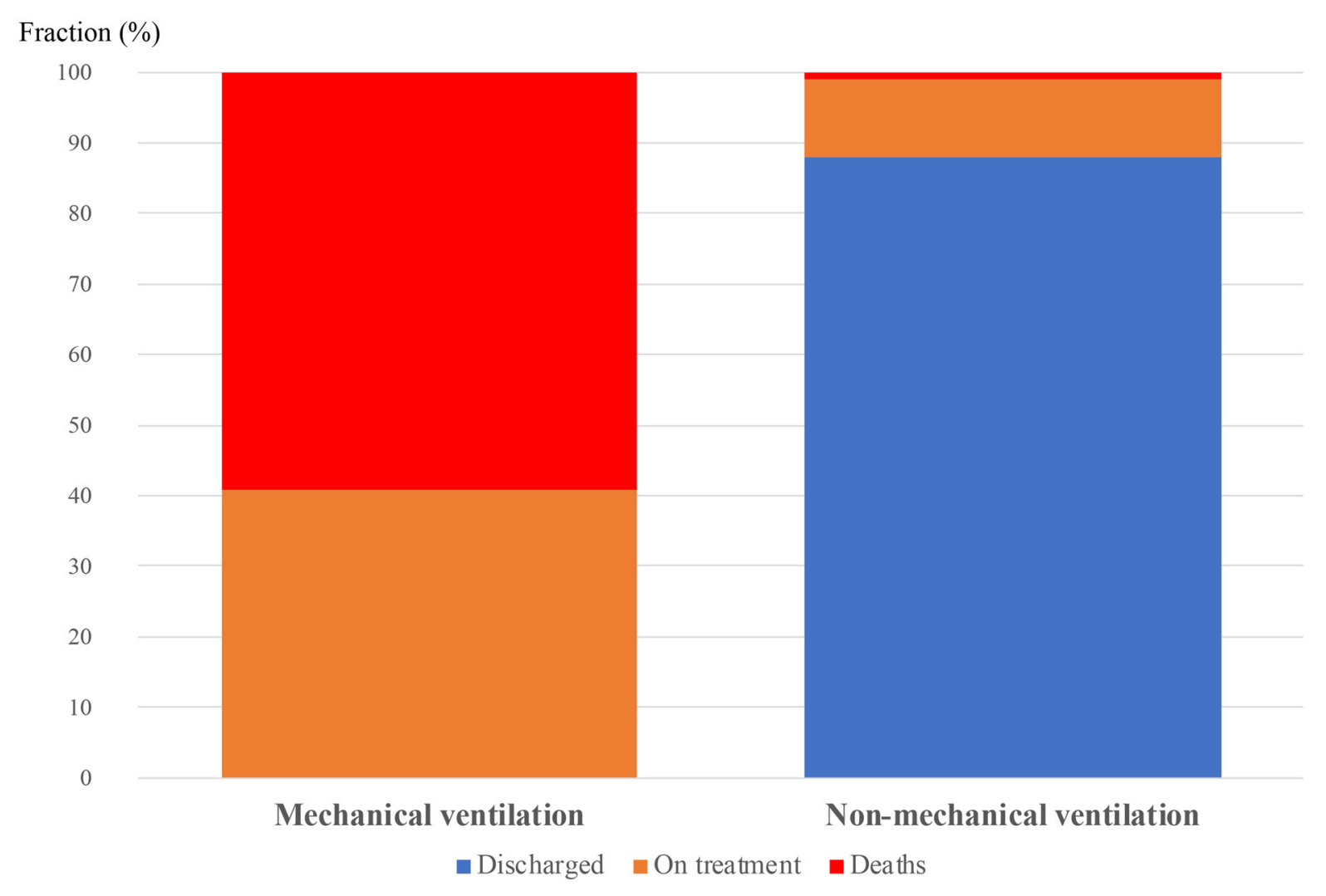

Figure 3. Clinical outcomes according to use of mechanical ventilation before TCZ administration.

Outcomes are shown for the 17 patients who were on mechanical ventilation and 62 patients who were not on mechanical ventilation before TCZ therapy._Proportion of deaths is in red, proportion of patients still in hospital is in orange, and proportion discharged from hospital is in blue._Mortality was greater in patients receiving mechanical ventilation ( $\mathrm{p}<0.001$ Fisher $\chi^{2}$ test). 
Table 3. Comparison of clinical and laboratory indices in patients who recovered or died

\begin{tabular}{|c|c|c|c|}
\hline Index & Death & Recovery (discharge) & $\mathbf{p}$ \\
\hline NEWS2 baseline & $\begin{array}{c}\mathrm{n}=11 \\
9(8: 10)\end{array}$ & $\begin{array}{l}\mathrm{n}=63 \\
4(3: 5)\end{array}$ & $<0.001^{\star}$ \\
\hline NEWS2, after TCZ & $\begin{array}{c}\mathrm{n}=11 \\
9(8: 9)\end{array}$ & $\begin{array}{l}\mathrm{n}=63 \\
2(1: 3)\end{array}$ & $<0.001^{\star}$ \\
\hline CRP mg/L baseline & $\begin{array}{c}n=11 \\
168(77: 205)\end{array}$ & $\begin{array}{c}n=63 \\
94(33: 148)\end{array}$ & NSD \\
\hline CRP mg/L, after TCZ & $\begin{array}{c}n=11 \\
51(23: 153)\end{array}$ & $\begin{array}{c}n=63 \\
13(5: 23)\end{array}$ & 0.001 \\
\hline Lymphocytes/uL baseline & $\begin{array}{c}n=11 \\
600(500: 700)\end{array}$ & $\begin{array}{c}\mathrm{n}=63 \\
900(700: 1200)\end{array}$ & 0.003 \\
\hline Lymphocytes/uL, after TCZ & $\begin{array}{c}n=11 \\
800(350: 1100)\end{array}$ & $\begin{array}{c}n=63 \\
1100(850: 1400)\end{array}$ & 0.05 \\
\hline
\end{tabular}

Presented are clinical and laboratory indices at baseline (just before TCZ administration) and one-to-two days after TCZ treatment in patients who died and patients who survived to discharge from hospital. Number of patients (n) and interquartile ranges (IQR) are presented. NSD -no statistical differences Data for total of 74 patients. Another 15 patients remain in hospital, at time of writing.

who survived and were discharged $(n=63)$ in the MV and No MV groups are presented in Table 3. Patients who remained on treatment in the hospital were excluded from this analysis. Median baseline NEWS2 scores were higher in those who died than in those who survived (9 vs 4; $\mathrm{p}<0.001$ ), as were median NEWS2 scores $1-2$ days after treatment with TCZ ( 9 vs $2 ; \mathrm{p}<0.001$ ). Median baseline CRP levels tended to be higher in those who died than in those who survived (168 vs $94 \mathrm{mg} / \mathrm{L})$; however, these differences did not reach statistical significance $(P=0.059)$. After TCZ treatment, median CRP levels fell $(P<0.001)$ in both groups but remained higher in those who died than in those who survived ( 51 vs $13 \mathrm{mg} / \mathrm{L} ; P=0.001$ ). Baseline lymphocyte counts were lower in lethal cases than in survivors (600 vs $900 / \mathrm{uL} ; P=0.003$ ), and remained lower in fatal cases than in survivors after treatment with TCZ (800 vs $1100 / \mathrm{uL} ; P=0.05)$. Baseline and after-treatment levels of LDH were not different between these groups (data not shown).

We found that absolute lymphopenia and elevated CRP levels immediately before treatment with TCZ could reliably distinguish survivors from those patients who died. Shown in Figure 4 are the survival curves for patients with known outcomes, divided into four groups according to absolute lymphocyte counts above or lower than $1000^{\prime} / \mathrm{uL}$ at baseline and CRP levels lower or greater than $30 \mathrm{mg} / \mathrm{L}$ at baseline. There were 41 patients in the highest CRP, low lymphocyte count group; 22 patients in the highest CRP normal lymphocyte count group, five patients in the lower CRP low 

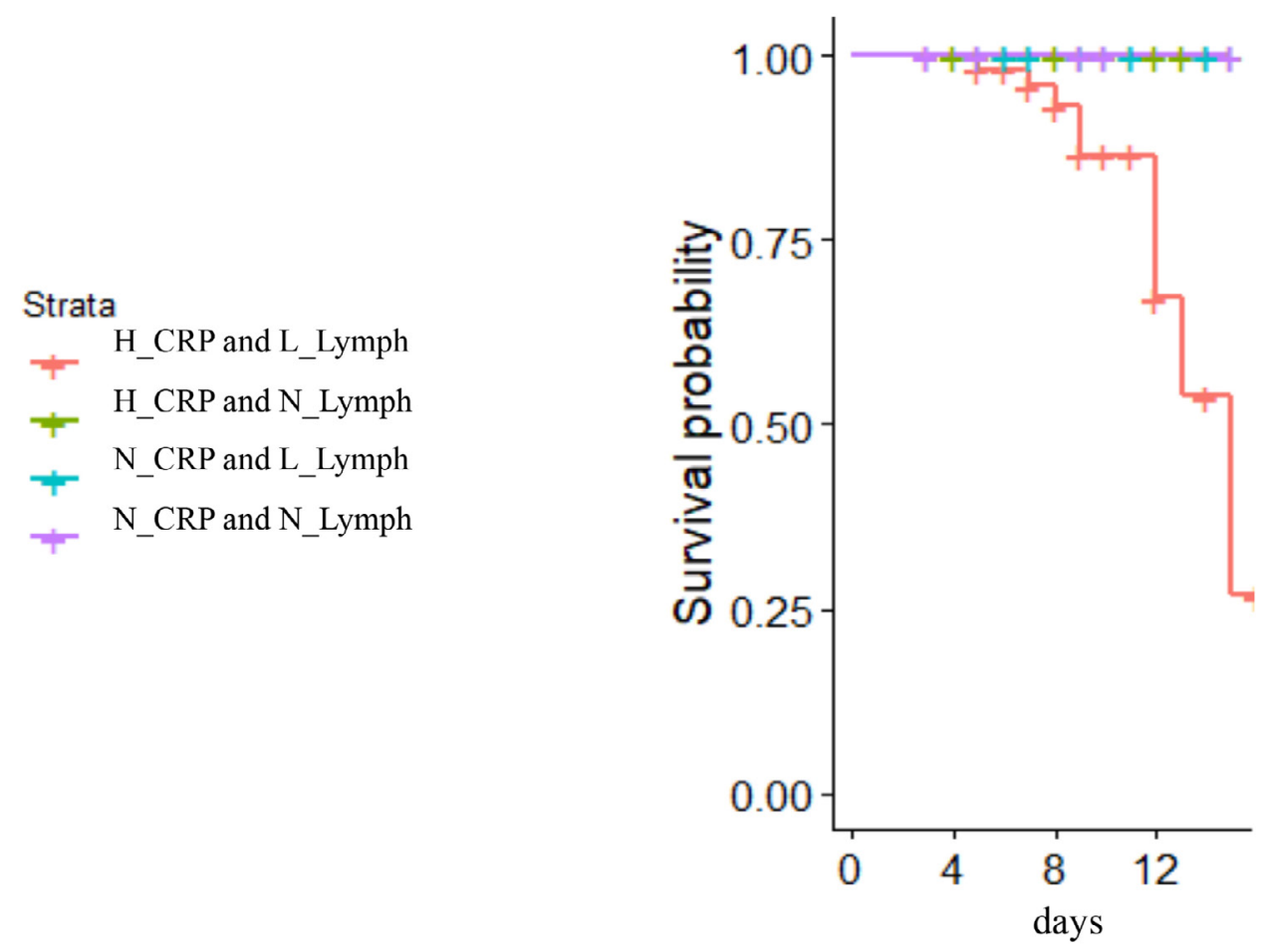

Figure 4. Mortality after TCZ is seen only in persons with highest CRP levels and low lymphocyte counts at treatment initiation.

Highest and lowest CRP levels were $>30$ and $\leq 30 \mathrm{mg} / \mathrm{L}$ respectively. Normal and low lymphocyte counts were $>1000$ and $<1000$ cells/uL respectively. There were 41 patients in the highest CRP/low lymphocyte count group (red); 22 patients in the highest CRP/normal lymphocyte count group (green); five patients in the lower CRP/low lymphocyte group (blue); and six patients in the lower CRP/normal lymphocyte count group (purple).

lymphocyte group; and six patients in the lower CRP normal lymphocyte count group. Mortality was only seen in patients who had both an absolute lymphocyte count $<1000 / \mathrm{uL}$ and a CRP $>30$ $\mathrm{mg} / \mathrm{L}$. Lymphopenia alone or elevated CRP levels without lymphopenia were not seen in fatal cases.

\section{DISCUSSION}

Here we report the outcomes of COVID-19 disease in individuals treated with the IL-6 receptor inhibitor, tocilizumab (TCZ).

The pathogenesis of severe COVID-19 disease is incompletely understood; however, emerging evidence that includes elevated plasma levels of IL-6 and elevated levels of soluble markers that are induced by IL- 6 (such as C reactive protein, ferritin, and D-dimer products of fibrinolysis $[\underline{10}, \underline{11}]$ ) suggest that IL-6 may play an important role in the morbidity outcome. In another setting of cytokine storm - that is, the storm syndrome seen after CAR-T cell therapy IL-6 receptor blockade-has been shown to be highly effective [ $[\underline{6}$. 
In two small series of COVID-19 cases that included 15 and 21 patients who received open label TCZ, there was an improvement in clinical course as well as, in some patients, in laboratory and radiographic abnormalities. Luo et al. [12] treated 15 patients with IV TCZ at varying doses from 80 to $600 \mathrm{mg}$, combining TCZ with methylprednisolone in eight and repeating TCZ dosing in five. They reported clinical improvement in one patient, stabilization in nine, and deterioration in five patients, which included three deaths. CRP levels fell in all patients and IL-6 levels rose in all but one patient. Increase in serum IL-6 is expected with TCZ administration as a result of receptor blockade [12]. Xu et al. [13] reported on 21 patients with severe COVID-19 pneumonia who were treated with IV TCZ $400 \mathrm{mg}$ in addition to treatment with lopinavir and methylprednisolone. Clinical improvement, as characterized by rapid decrease in temperature, improvements in oxygenation, and in chest CT abnormalities were reported; CRP levels fell in all patients and 19 of 21 were discharged from the hospital.

In the present study we investigated the results of TCZ treatment in a larger cohort of 89 patients with COVID-19 pneumonia. Here we report the early effects of TCZ administration on clinical and laboratory outcomes. All of our patients had SARS-2 infection, as revealed by viral sequences in respiratory secretions, and all had pneumonia, as evidenced by CT scan results. Severity of disease varied, with 17 patients requiring mechanical ventilation support before administration of TCZ. Although all patients were treated with drugs often used for treatment of SARS-2 infection such as antimalarials (chloroquine or hydroxychloroquine), azithromycin, or an antiviral protease inhibitor (lopinavir/ritonavir), none of these agents had confirmed clinical utility in treatment

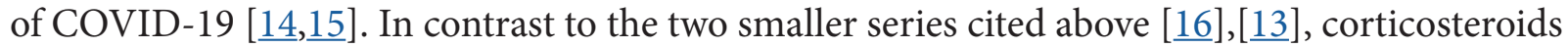
were not given to these patients during TCZ administration or in the two days following. The role of corticosteroids in the treatment of COVID-19 is unproven $[\underline{17}, \underline{18}]$.

Our patients with COVID-19 pneumonia had a profound inflammatory disease. Specifically, all patients had elevated levels of $C$ reactive protein exceeding the $6 \mathrm{mg} / \mathrm{L}$ upper limit of normal in our laboratories. Plasma IL-6 levels were also elevated in all patients, exceeding the laboratory normal reference range of $6.4 \mathrm{pg} / \mathrm{mL}$, and circulating lymphocyte numbers were diminished in most patients. The drivers of inflammation and lymphocytopenia in COVID-19 are not well understood yet, but the preliminary data generated to date by this and other [16], [1] studies suggest that interfering with IL-6 activity improves these indices. The rapid improvement in NEWS2 scores after TCZ administration suggests that clinical improvement is linked to resolution of inflammation and that IL-6 activity is an important driver of morbidity in SARS-2 infection. In our series, outcome of disease in treated patients who did not require mechanical ventilation was largely favorable, with nearly $90 \%$ of patients surviving to discharge and only one death among 72 treated patients at the time of writing. Clinical outcomes in patients who were receiving mechanical ventilation at initiation of TCZ treatment were not as good. Although 10 of 17 patients receiving mechanical ventilation experienced an improved NEWS2 score 1-2 days after TCZ treatment (four of these 10 patients died), overall there were 10 deaths in the entire group, while seven patients remained in hospital.

While lymphocytopenia and elevated C reactive protein are common in COVID-19, mortality was only seen in patients who had both low lymphocyte counts $(<1000 / \mathrm{uL})$ and profoundly elevated CRP (>30 mg/L) before treatment with TCZ. 
Although our results suggest that TCZ therapy is beneficial for hospitalized patients with COVID-19, this report has important limitations. First, this was a retrospective study conducted in a heterogeneous group of patients. Interpretation of this study is also limited by the absence of a control group that did not receive TCZ. Nonetheless the temporal improvement in clinical and laboratory scores suggests that these are related to TCZ administration. Controlled studies are needed to determine whether cytokine blockade and in particular blockade of IL-6, confers benefit to persons with COVID-19. Such studies are ongoing and their findings are eagerly awaited. Our data suggest that for COVID-19 patients requiring mechanical ventilation, IL-6 blockade alone may be insufficient; other interventions are necessary.

\section{CONFLICTS OF INTEREST}

We declare no competing interest.

\section{ACKNOWLEDGEMENTS}

We would like to thank Dr. Leonid Margolis for encouragement and for assistance in manuscript preparation. We would thank Dr. Alexey Mazus for encouragement and help in coordinating this research.

\section{REFERENCES}

1. Zhou P, Yang XL, Wang XG, Hu B, Zhang L, Zhang W, Si HR, Zhu Y, Li B, Huang CL, Chen HD, Chen J, Luo Y, Guo H, Jiang RD, Liu MQ, Chen Y, Shen XR, Wang X, Zheng XS, Zhao K, Chen QJ, Deng F, Liu LL, Yan B, Zhan FX, Wang YY, Xiao GF, Shi ZL. A pneumonia outbreak associated with a new coronavirus of probable bat origin. Nature. 2020;579(7798):270-3. Epub 2020/02/06. doi: 10.1038/s41586-020-2012-7. PubMed PMID: 32015507; PMCID: PMC7095418.

2. Letko M, Marzi A, Munster V. Functional assessment of cell entry and receptor usage for SARS-CoV-2 and other lineage B betacoronaviruses. Nat Microbiol. 2020;5(4):5629. Epub 2020/02/26. doi: 10.1038/s41564-020-0688-y. PubMed PMID: 32094589; PMCID: PMC7095430.

3. Hoffmann M, Kleine-Weber H, Schroeder S, Kruger N, Herrler T, Erichsen S, Schiergens TS, Herrler G, Wu NH, Nitsche A, Muller MA, Drosten C, Pohlmann S. SARS-CoV-2 Cell Entry Depends on ACE2 and TMPRSS2 and Is Blocked by a Clinically Proven Protease Inhibitor. Cell. 2020;181(2):271-80 e8. Epub 2020/03/07. doi: 10.1016/j.cell.2020.02.052. PubMed PMID: 32142651; PMCID: PMC7102627.

4. Wang X, Fang X, Cai Z, Wu X, Gao X, Min J, Wang F. Comorbid Chronic Diseases and Acute Organ Injuries Are Strongly Correlated with Disease Severity and Mortality among COVID-19 Patients: A Systemic Review and Meta-Analysis. Research (Wash D C). 2020;2020:2402961. Epub 2020/05/08. doi: 10.34133/2020/2402961. PubMed PMID: 32377638; PMCID: PMC7187729.

5. Bonafe M, Prattichizzo F, Giuliani A, Storci G, Sabbatinelli J, Olivieri F. Inflamm-aging: Why older men are the most susceptible to SARS-CoV-2 complicated outcomes. Cytokine Growth Factor Rev. 2020;53:33-7. Epub 2020/05/12. doi: 10.1016/j.cytogfr.2020.04.005. PubMed PMID: 32389499; PMCID: PMC7252014. 
6. Murthy H, Iqbal M, Chavez JC, Kharfan-Dabaja MA. Cytokine Release Syndrome: Current Perspectives. Immunotargets Ther. 2019;8:43-52. Epub 2019/11/23. doi: 10.2147/ITT.S202015. PubMed PMID: 31754614; PMCID: PMC6825470.

7. Temporary guidelines for the prevention, diagnosis and treatment of new coronovirus infection (COVID-19) [Internet]. Ministry of Health of the Russian Federation; 2020 [updated 2020 Apr 28; cited 2020 May 7]. Available from: https://static-1.rosminzdrav. $\mathrm{ru} /$ system/attachments/attaches/000/050/122/original/28042020_\%D0\%9CR_ COVID-19_v6.pdf.

8. Martin-Rodriguez F, Lopez-Izquierdo R, Del Pozo Vegas C, Delgado Benito JF, Carbajosa Rodriguez V, Diego Rasilla MN, Martin Conty JL, Mayo Iscar A, Otero de la Torre S, Mendez Martin V, Castro Villamor MA. Accuracy of National Early Warning Score 2 (NEWS2) in Prehospital Triage on In-Hospital Early Mortality: A Multi-Center Observational Prospective Cohort Study. Prehosp Disaster Med. 2019;34(6):610-8. Epub 2019/10/28. doi: 10.1017/S1049023X19005041. PubMed PMID: 31648657.

9. Martin-Rodriguez F, Lopez-Izquierdo R, Del Pozo Vegas C, Sanchez-Soberon I, Delgado-Benito JF, Martin-Conty JL, Castro-Villamor MA. Can the prehospital National Early Warning Score 2 identify patients at risk of in-hospital early mortality? A prospective, multicenter cohort study. Heart Lung. 2020;49(5):585-91. Epub 2020/03/15. doi: 10.1016/j.hrtlng.2020.02.047. PubMed PMID: 32169257.

10. Emery P, Keystone E, Tony HP, Cantagrel A, van Vollenhoven R, Sanchez A, Alecock E, Lee J, Kremer J. IL-6 receptor inhibition with tocilizumab improves treatment outcomes in patients with rheumatoid arthritis refractory to anti-tumour necrosis factor biologicals: results from a 24-week multicentre randomised placebo-controlled trial. Ann Rheum Dis. 2008;67(11):1516-23. Epub 2008/07/16. doi: $\underline{10.1136 /}$ ard.2008.092932. PubMed PMID: 18625622; PMCID: PMC3811149.

11. Bi X, Su Z, Yan H, Du J, Wang J, Chen L, Peng M, Chen S, Shen B, Li J. Prediction of severe illness due to COVID-19 based on an analysis of initial Fibrinogen to Albumin Ratio and Platelet count. Platelets. 2020;31(5):674-9. Epub 2020/05/06. doi: 10.1080/09537104.2020.1760230. PubMed PMID: 32367765; PMCID: PMC7212543.

12. Nishimoto N, Terao K, Mima T, Nakahara H, Takagi N, Kakehi T. Mechanisms and pathologic significances in increase in serum interleukin-6 (IL-6) and soluble IL-6 receptor after administration of an anti-IL-6 receptor antibody, tocilizumab, in patients with rheumatoid arthritis and Castleman disease. Blood. 2008;112(10):3959-64. Epub 2008/09/12. doi: 10.1182/blood-2008-05-155846. PubMed PMID: 18784373.

13. Xu X, Han M, Li T, Sun W, Wang D, Fu B, Zhou Y, Zheng X, Yang Y, Li X, Zhang X, Pan A, Wei H. Effective treatment of severe COVID-19 patients with tocilizumab. Proc Natl Acad Sci U S A. 2020;117(20):10970-5. Epub 2020/05/01. doi: 10.1073/ pnas.2005615117. PubMed PMID: 32350134; PMCID: PMC7245089.

14. Hashem AM, Alghamdi BS, Algaissi AA, Alshehri FS, Bukhari A, Alfaleh MA, Memish ZA. Therapeutic use of chloroquine and hydroxychloroquine in COVID-19 and other viral infections: A narrative review. Travel Med Infect Dis. 2020;35:101735. Epub 2020/05/11. doi: 10.1016/j.tmaid.2020.101735. PubMed PMID: 32387694; PMCID: 
PMC7202851.

15. Wen CY, Xie ZW, Li YP, Deng XL, Chen XT, Cao Y, Ou X, Lin WY, Li F, Cai WP, Li LH. [Real-world efficacy and safety of lopinavir/ritonavir and arbidol in treating with COVID-19 : an observational cohort study]. Zhonghua Nei Ke Za Zhi. 2020;59(0):E012. Epub 2020/05/11. doi: 10.3760/cma.j.cn112138-20200227-00147. PubMed PMID: 32388937.

16. Luo P, Liu Y, Qiu L, Liu X, Liu D, Li J. Tocilizumab treatment in COVID-19: A single center experience. J Med Virol. 2020;92(7):814-8. Epub 2020/04/08. doi: 10.1002/ jmv.25801. PubMed PMID: 32253759; PMCID: PMC7262125.

17. Liu K, Fang YY, Deng Y, Liu W, Wang MF, Ma JP, Xiao W, Wang YN, Zhong MH, Li CH, Li GC, Liu HG. Clinical characteristics of novel coronavirus cases in tertiary hospitals in Hubei Province. Chin Med J (Engl). 2020;133(9):1025-31. Epub 2020/02/12. doi: 10.1097/CM9.0000000000000744. PubMed PMID: 32044814; PMCID: PMC7147277.

18. Wang D, Hu B, Hu C, Zhu F, Liu X, Zhang J, Wang B, Xiang H, Cheng Z, Xiong Y, Zhao Y, Li Y, Wang X, Peng Z. Clinical Characteristics of 138 Hospitalized Patients With 2019 Novel Coronavirus-Infected Pneumonia in Wuhan, China. JAMA. 2020. Epub 2020/02/08. doi: 10.1001/jama.2020.1585. PubMed PMID: 32031570; PMCID: PMC7042881.

\section{FOOTNOTES}

Submitted June 12, 2020 | Accepted June 22, 2020 | Published October 2, 2020

\section{COPYRIGHT}

Copyright (C) 2020 Pathogens and Immunity. This is an open-access article distributed under the terms of the Creative Commons Attribution 4.0 International License. 